\title{
Alfonso Reyes y el cine del porvenir
}

\section{Alfonso Reyes and the future's cinema}

\author{
Betina Keizman ${ }^{1}$ \\ Universidad Adolfo lbáñez. Facultad de Artes Liberales. Santiago, Chile. \\ betkeiz@yahoo.com
}

\section{Resumen}

Este artículo se propone situar la reflexión de Alfonso Reyes sobre el cine en el marco de las recepciones del primer cine, considerando también cómo esta reflexión se articula en relación con el pensamiento crítico del escritor mexicano. En particular, se analiza el modo en que, por vía de la especulación, Reyes ensaya posibles redefiniciones para una nueva distribución de lo sensible y de las artes, de los valores cognitivos y expresivos de la luz y de los vínculos arte-ciencia. Lo que se lee en Reyes es un esfuerzo por pensar nuevas formas de inventiva que se desprenden (o podrían desprenderse) del arte cinematográfico.

Palabras clave: Alfonso Reyes, cine, ciencia, humanismo.

\section{Abstract}

The present paper considers placing Alfonso Reyes's thought regarding cinema in the frame of the first cinema receptions, considering also how this reflection is joint to the Mexican's criticism thought. Especially, they analyze the way that, through speculation, Reyes tries possible redefinitions for a new distribution of the sensitive and the arts, of the cognitive and sensitive light's values and of the links between arts and science. What you read in Reyes is an effort for thinking new inventions forms that comes out of (or might come out of) the cinematographic art.

Keywords: Alfonso Reyes, Cinema, Science, Humanism.

1 Este artículo se desarrolló en el marco de proyecto Fondecyt regular $\mathrm{n}^{\circ} 1130563$ "Relaciones Cine-Literatura en la Producción de Escritores de Argentina, México y Chile entre 1915 Y 1940”. 
En 1895 se produce la primera exhibición pública de los hermanos Lumière, en un sótano del Gran Café, ubicado en Paris, en Boulevard des Capucines. El dueño del lugar, un italiano llamado Volpini, se niega a aceptar un pago del 20\% de los ingresos y exige una renta de 30 francos diarios, y un contrato anual. Veinte años después y aún bajo los efectos de la discusión sobre la calidad y condición artística del nuevo medio, Alfonso Reyes se hace cargo en el semanario España, bajo el pseudónimo "Fósforo" que comparte con Martín Luis Guzmán, de la que celebra como la primera columna de crítica cinematográfica en ese idioma: "Frente a la pantalla”. Esos veinte años han confirmado el cine como espectáculo de masas, con salas de proyección en todo el mundo, y Fósforo publica alrededor de treinta notas en el semanario España, y a partir de 1916, manteniendo el pseudónimo pero en un trabajo individual, Reyes continúa escribiendo sobre cine en el diario El imparcial. A esta segunda experiencia, seguirá la tercera y última, un breve paso (con un par de artículos), en la columna "Revista cinematográfica", en la Revista General de la Casa Calleja. Estos ensayos, críticas de películas y reflexiones generales sobre la nueva industria y su desarrollo en España, comentan y valoran, entre otras, obras cinematográficas como la italiana Cabiria, el serial norteamericano El cofre negro, la danesa El fantasma del batelero, el serial francés Fantomas, la alemana El Golem, la inglesa Las luces de Londres y el serial norteamericano Los misterios de Nueva York. ${ }^{2}$ Esas primeras notas critican el melodrama de las películas italianas, encumbran el dinamismo y la fuerza del ya pujante cine americano, demuestran conocer las producciones francesas y alemanas y son, en definitiva, una defensa entusiasta de la condición artística del nuevo medio.

En un principio, se diría que la reseña cinematográfica es un medio de subsistencia para los entonces jóvenes exiliados mexicanos en España, sin embargo, en el caso de Reyes, la amplitud de sus intereses y de sus proyectos relativiza el alcance de esta afirmación. A lo largo de los años, se referirá al cine con una persistencia que pasa inadvertida en el caudal verdaderamente portentoso de su poligrafismo, pese a que en los ensayos y notas posteriores a sus años en España se decanta un balance de lo que la producción cinematográfica implica para el autor regiomontano ${ }^{3}$. La contemporaneidad del cine estimula la atención de Reyes y la necesidad de nutrir su reflexión de las experiencias propias de su tiempo. Pero más excepcional que el

2 Esta selección de textos sobre cine, Reyes la publica luego en la primera edición de Simpatías y diferencias (1922). Martín Luis Guzmán incluirá los textos que se adjudica en A orillas del Hudson (1920). Para las citas, seguimos la edición de Manuel González Casanova de El cine que vio Fósforo, quien realiza un minucioso trabajo de investigación y cotejo entre las ediciones periodísticas originales, las versiones que aparecen en las antologías y las que luego Alfonso Reyes incluye en sus obras completas.

3 Sin ser exhaustivos, algunos de los ensayos que se refieren al cine, posteriores al período español, son los siguientes: "Las nuevas artes", (publicado originalmente en Tricolor, México, en 1944) en Los trabajos y los días, incluido en OC. Vol IX; "La garza Greta Garbo", (publicado originalmente en La Nación, Bs. As., 1932), en Historia natural deas Laranjeiras, incluido en OC. Vol IX; "La escultura de lo fluido", en Tren de ondas, incluido en OC VIII; "México en el cine: La obra de Einstein, perdida", de 1932, en A lápiz, incluido en OC. Vol VIII; "Notas sobre cine" (originalmente publicado como "El cine sonoro", Cine Mundial, Nueva York, II, 1932), en Tren de ondas, incluido en OC VIII; "Un drama para el cine", 1932, en Tren de ondas, incluido en OC VIII. 
interés por un medio cuya irrupción provocó una partición de aguas entre artistas e intelectuales, entre quienes lo aborrecieron o lo festejaron ${ }^{4}$, Reyes está entre los primeros que perciben de un modo inequívoco que la irrupción del cine modifica la distribución y el equilibrio de las artes, y volverá una y otra vez a la cuestión de lo que a cada arte le corresponde. Por otro lado, el cine incipiente le interesa por tres razones: su carácter dinámico, su lazo con la ciencia (y aquí su vinculo con lo real), y porque lo percibe como un terreno especulativo por excelencia.

\section{La distribución de lo sensible}

Si el cine es un arte -y Reyes defiende esta premisa con fervor-, es evidente que su surgimiento reclama una redistribución de los usos y de las dimensiones sensibles que a cada arte se atribuye. En su contexto original, la querella respecto de la diferenciación entre cine, teatro y literatura acompañó los primeros pasos del cine apenas se vislumbraron sus posibilidades más allá del espectáculo de feria ${ }^{5}$. Ya en "Manifiesto de las siete artes" de Canudo, como en la mayor parte de los artículos iniciales de corte estético sobre cine, se repasan las características de cada forma artística en relación con el espacio y con el tiempo. Esta definición de lo que era propio de cada arte estaba orientada por la necesidad de precisar la identidad cinematográfica, el hallazgo de una forma de expresión, de técnicas y de realización que se adaptara al medio, y que a la vez lo configurara como tal. Vale decir que este intento de definición que se multiplica en ensayos, reseñas y comentarios de la más diversa índole, no implicaba necesariamente un cuestionamiento del sistema general de las artes; los intelectuales, escritores y artistas apenas consideraron las secuelas de la inclusión de este nuevo "actor", poco se cuestionaron sobre cómo este medio modificaba el equilibrio y la posible ontología de las prácticas estéticas ya existentes. Para que esta posibilidad fuera considerara, había que asumir una postura de audacia intelectual que Reyes condensa porque, aunque insatisfecho con la calidad artística del cine primitivo, intelectualmente no deja de razonar lo que para él es un colofón lógico e incuestionable del nacimiento del cine como arte: una modificación en todas las artes ${ }^{6}$.

4 Entre otras, puede consultarse: Le cinéma: naissance d’un art. 1895-1920 y, para la recepción en Latinoamérica, la antología de Jason Borge, Avances de Hollywood: crítica cinematográfica en Latinoamérica 1915-1945, la de Wolfgang Bongers, María José Torrealba y Ximena Vergara, Archivos y letrados. Escritos sobre cine en Chile: 1908-1940, y la de Manuel González Casanova, Por la pantalla. Génesis de la crítica cinematográfica en México 1917-1919.

5 Incluso en un libro muy posterior, y que implica un grado de especialización extremo, como es Historia del cine mundial de Georges Sadoul, el autor comienza la "Introducción" con las siguientes dos frases: "Nació un arte ante nuestros ojos. La pintura y la música existen desde hace millones de años" [1].

6 Entre quienes sí percibieron este "efecto vibratorio" sobre todas las artes, está, evidentemente, Walter Benjamin, quien refiriéndose a la fotografía y su estatuto de arte plantea que muchas veces no se reflexionó "la cuestión previa sobre si la invención de la primera no modificaba por entero el carácter del segundo" (32) y Paul Valery, citado por Benjamin en el epígrafe de su ensayo, quien cuenta con que "novedades tan grandes transformen toda la técnica de las artes y operen por tanto sobre la inventiva" (160-1). 
La prueba de que el cine era un arte residía en la imposibilidad de hablar sobre cine "sin filosofar sobre estética" (Reyes, "Notas sobre cine", OC VIII 379) y Reyes postuló dos épocas, un antes del cine y un después del cine, que indicó como a.C y d.C para señalar hasta qué grado consideraba que el cine era un hito de la historia de la cultura. Pero sobre todo, la exigencia de que el cine encontrara su propio lenguaje supone para Reyes un trabajo de la crítica, una necesidad desde la que puede leerse su propio aporte en la tarea, siendo para él, la crítica y la reflexión, elementos sustanciales y formativos del desarrollo de cualquier arte. Por eso, el trabajo de Reyes en su primera etapa como crítico de cine en publicaciones periódicas no se propone solamente educar a los espectadores sino también -en un registro que se acentúa en ensayos posteriores- se trata de pensar y aportar como humanista, desde su función de artista e intelectual, al desarrollo del cine. Lo que para muchos fue la amenaza de "la alianza natural" de los nuevos medios con "la necedad de las multitudes" (74) (como indica Baudelaire respecto de la fotografía), para Reyes es el descubrimiento de un elemento clave, instrumento "transmisor" de carácter excepcional: "Nuestra civilización cuenta, entre otros, con seis medios principales para la transmisión de la cultura, más o menos sustentados todos en la palabra: la Escuela, la Prensa, el Teatro, el Museo, el Cine y la Radio" (Reyes, "Las nuevas artes", OC XIX 400). La educación por el arte es fundamental en el proyecto humanista, estético-formativo y pedagógico al que Reyes dedicó su vida, por eso es justificable que el cine atraiga una y otra vez su reflexión. Busca entender, pero también orientar y construir a partir de su propia intervención reflexiva, tal vez con un candor que hoy puede resultar anacrónico, pero tampoco tan ingenuo a la luz de las intervenciones de política cultural y diplomáticas que también formaron parte del terreno de acción del pensador mexicano. ${ }^{7}$ No es otra cuestión la que destaca Ignacio Sánchez Prado al señalar lo siguiente:

el ejercicio performativo de la cultura es una de las estrategias centrales del ethos intelectual de Reyes [...] la "tradición clásica" significa la fundación propiamente dicha de la crítica literaria como instrumento simultáneamente educativo y político, una forma de concebir la literatura no solo como un vehículo de los valores de la República, algo que ya sabían los liberales del XIX, sino como un espacio público autónomo donde dichos valores tienen una genealogía y son objeto de discernimiento y consideración por parte de los miembros de la polis. Para Reyes, la crítica literaria no solo acarrea una función pedagógica llana, sino que se entiende como uno de los ejercicios centrales de la práctica intelectual (10-1).

7 Esta importancia del cine por su carácter masivo se manifiesta también en otra serie de intervenciones de Reyes, las diplomáticas y las que consideran el cine como una puerta al mundo para México. Ver "México en el cine: La obra de Einstein, perdida" (de 1932, incluido en OC. Vol VIII) y el ensayo "Alfonso Reyes, censor de película", por Aurelio de los Reyes García-Rojas, donde también se reproduce una carta de Reyes del año 1926 que registra los intentos del entonces diplomático por impulsar la filmación de una película francesa de propaganda favorable a México. 
Esta afirmación puede extenderse a todas las formas de la crítica cultural que Reyes encara, y que para él suponen una práctica de lo literario, y en ese sentido, el cine aparece como un punto neurálgico, por supuesto conflictivo por sus lazos con la Industria y con las formas masivas y populares de la cultura que necesariamente desafían las fuerzas y la orientación del proyecto del mexicano.

Volviendo al camino que va de la diferenciación entre las artes a la modificación de las artes, en sus primeras reseñas, en un artículo reconocido por José Luis Guzmán, Fósforo traza las diferencias entre cine y danza ("Las leyes del ritmo y la dificultad de la técnica acortan el vuelo a la danza. El cine no conoce barreras; su empleo del acto brusco como elemento de belleza mecánica es ilimitado; supera con mucho, por ejemplo, los mayores atrevimientos de la música moderna en el uso de lo disonante y lo arrítmico." (Casanova 143)), recordará la división de las artes de Stevenson, quien "dividía las artes en artes del tiempo (la música, la literatura), artes del espacio (la pintura, la escultura, la danza, la pantomima) y artes mixtas (el teatro)" (Casanova 155) y señalará el absurdo de la representación teatral en el cine, una experiencia completamente diferente, con un espacio reducido y un uso de primeros planos con nuevas exigencias de expresión. Más de 25 años después, en un ensayo de 1944, "Las nuevas artes", Reyes expone un verdadero balance del impacto de las nuevas artes en el sistema general de las artes. Allí propone la radio como una reformulación de la antigua retórica que, al modo aristotélico, sería una práctica de persuasión en el lenguaje. En esta nueva distribución, el cine sería una actualización de la épica, que hace necesaria una redefinición de lo propiamente literario que se desplazaría hacia otras zonas, en una ruta que en mucho coincidirá con la empresa literaria de Reyes: el centauro de los géneros, esa "comunicación de especies intelectuales" como una de las formas literarias -que Reyes proclama contemporáneas- por excelencia. ${ }^{8}$ Lo que Reyes reconsidera a la luz de la presencia del cine es lo que tradicionalmente se entendía por funciones literarias: la lírica, la épica-novelística y la dramática, tragedia o comedia. Para Reyes, estas funciones tradicionales se modifican con las nuevas artes: "creemos, en efecto, que la función épico-narrativa poco a poco derivará hacia el cine. Hay en ella elementos descriptivos que la literatura solo da de manera muy indirecta y equívoca y que la ejecución visual del cine comunica a la perfección" (Reyes, "Las nuevas artes" Ibíd.). ${ }^{9}$ Anuncia entonces un retorno a la esencia oral de la literatura, que se iría concentrando "en el sustento verbal: la poesía más pura o desasida de narración, y la comunicación de especies intelectuales" (403). En "La

8 Es llamativo que pocas veces se considere que la famosa definición que Reyes propone de la forma ensayística -el centauro de los géneros- se presenta en un artículo sobre las nuevas artes, elaborado en una reflexión sobre el cine y la radio.

9 Esta afirmación es afín al movimiento que se da en el cine de la época. Baste recordar que Bazin rompe con los teóricos de la vanguardia, negando el desarrollo de un cine puro, en una progresión hacia un estilo narrativocinematográfico cada vez más realista. Ismael Xavier indica que ese giro "propone una afinidad esencial entre la narración cinematográfica y determinadas características básicas de un estilo novelesco "objetivo" y de "reportaje" próximo de los escritores norteamericanos del siglo XX (John Dos Passos, Hemingway)” (106). 
radio y el habla americana" la necesidad de estudiar una nueva distribución de las artes será aún más explicita: "Está haciendo falta escribir un Nuevo Laocoonte" (Reyes, OC IX 441).

\section{Especulación: Dinamismo y luz, arte y ciencia}

En un conocido dibujo de Carlos Fuentes, éste representa a Reyes vestido con toga, ceñudo, un alter ego mexicanizado de Sócrates. El acierto de la imagen no podría ser mayor, no solamente por los indiscutibles lazos de Reyes con la cultura helénica, sino también por su impulso pedagógico y el espíritu omnívoro que gusta de paladear todas las zonas de la cultura, entendida en su sentido más amplio, incluso para un espíritu tan clásico como el de Alfonso Reyes. Sus obras completas constan de veintiséis tomos y quedan muchos textos por incluir. La tarea de organizar las zonas de su reflexión es ardua, y tal vez fútil para un pensamiento que vive en la diversidad y la amplitud. Impulsado por necesidades metodológicas, didácticas y de reflexión, Reyes busca limitar, sentar las particularidades, pero toda su fuerza está en establecer lazos, vincular zonas, concebir formas de reflexión más complejas y completas. Una de las definiciones de humanismo que el mismo Reyes propone insinúa esta dialéctica:

Hoy el humanismo no es, pues, un cuerpo determinado de conocimientos, ni tampoco una escuela. Más que como un contenido específico, se entiende como una orientación. La orientación está en poner al servicio del bien humano todo nuestro saber y todas nuestras actividades. Para adquirir esta orientación no hace falta ser especialista en ninguna ciencia o técnica, pero sí registrar sus saldos. Luego es necesario contar con una topografía general del saber y fijar su sitio a cada noción. Por lo demás, toda disciplina particular, por ser disciplina, ejercita la estrategia del conocimiento, robustece la aptitud de investigación y no estorba, antes ayuda, al viaje por el océano de las humanidades. (Reyes, "Palabras sobre el humanismo". En Andrenio: perfiles del hombre. OC XX 403) ${ }^{10}$.

También el cine, Reyes busca incluirlo en este ambicioso proyecto humanista, por la vía de la reflexión, e incluso una cierta fascinación, por dos aspectos esenciales a su comprensión del arte, y que también son intrínsecos a la constitución misma del cine como técnica y como práctica cultural: el dinamismo, entendido como movimiento puro -lo propio de la vida- y la unión de la ciencia-técnica y el arte.

10 Como muestra de esta tensión, intrínseca al pensamiento de Reyes, baste contrastar el esfuerzo de sistematización que se propone en El deslinde. Prolegómenos a la teoría literaria, que Goic destaca como "una tentativa, verdaderamente kantiana, de establecer los límites y la autonomía de la literatura en sentido estricto de una gama variada de saberes "literarios"... no la teoría literaria misma sino su propedéutica: mera distinción de su objeto en un campo de vastas contaminaciones" (73). 
Las tres primeras décadas del siglo XX entonaron su canto a la velocidad bajo el llamado al dinamismo, un tópico reiterado en las vanguardias, que tuvo en el futurismo su mayor exponente: “Tienen razón los futuristas; piensan como el doctor de la Iglesia, que la suprema perfección está en ser activo; que todo es acto de la divinidad; que nos salvaremos por el movimiento, por lo cinemático y lo dinámico" (Casanova 132). Sin embargo, el sentido de este dinamismo rebasa, en Reyes, los alcances que el término tiene en el diccionario de la vanguardia, porque en su caso se trata no solamente de una reivindicación de lo vital sino de la búsqueda de un arte que se involucre con lo significativo-humano. Tampoco pide otra cosa cuando se aproxima al mundo helénico: "Hay que contemplar la antigüedad con ojos vivos y alma de hombres...Hay que volver a sentir las cosas de la epopeya como la sentían el poeta y su gente" (Reyes, "La estrategia del "gaucho" Aquiles". OC VII 254). Esta actualización vital y dinámica es intrínseca a la propuesta humanista de Reyes y a su concepción de las artes, y es bajo su exigencia que debe descifrarse el tipo de desafío que el cine abre ante Reyes.

El dinamismo y el movimiento que la vanguardia ensalza tiene sus raíces en atrapar y ser la vida, ese "arte total al que, desde siempre, han tendido todas las artes" (Canudo 16), pero la vanguardia actualiza esta reivindicación como una acción propia de la modernidad, como expresión de una época en que el arte abandonaría el recinto de la convención, la producción y la academia, ${ }^{11}$ mientras que para Reyes, ese dinamismo es lo atemporal, lo propio de lo humano, una continuación, un regreso a las fuentes y un enlace. Esta reformulación de la vanguardia en relación con el propio proyecto humanista, también la encontramos en un ensayo de 1924 titulado "Contra el museo estático", incluido en Calendario, donde el eco contemporáneo propone un regreso a fuentes ancestrales de la cultura, a ese momento utópico en que el arte vive y es en la comunidad:

¿Qué idea de la vida puede darme esos catorce jarrones chinos formados en hilera, y ni siquiera expuestos al mercado? ¿Esos tres mandarines metidos como momias tras de la vitrina?....Los museos debieran confundirse con la vida misma. El señor mandarín estaría sentado en su sillón, bebiendo su te, junto a la mesa, en la sala de los jarrones. En rigor, a la entrada de la galería debieran proporcionarme un traje de mandarín para que pudiera yo sentirme chino un instante... Queremos quemar los museos y fundar el museo dinámico, el cine de bulto, el filme de tres dimensiones...Queremos el museo-teatro-circo, con derecho a saltar al plano de las ejecuciones (cit. en Perea 25).

11 Patrick Duffey señala que este culto de la velocidad expresó en la época nuevas formas de percepción y de producción artística vinculadas con el cine mudo. 
Para Reyes, el movimiento en el cine no lo es solamente en cuanto a su capacidad de reproducción de lo real, sino sobre todo en lo que respecta a una vitalidad que alcanza al espectador. De nuevo, podemos medir la reivindicación de ecos vanguardistas: "género genuinamente cinematográfico. El perro, el caballo, el auto, el coche, la bicicleta, el aeroplano, el globo, el hidroplano" (Casanova 136), aunque es elocuente que Reyes busque incorporar este dinamismo en el centro de su propio pensamiento, marcado por la cultura helénica, al señalar hasta qué punto esa movilidad supone una recepción que anima la catarsis, porque a diferencia de las películas italianas, que identifica extrañamente con el teatro de Ibsen por el registro negativo que dejarían en el espectador y que para Reyes supone una fuerza pesimista, interior e individual, la experiencia de dinamismo involucra al espectador insuflándolo de una intensidad vital que por sí misma rezuma lo que Reyes le pide a la cultura como forma de vida. De ese modo, la participación afectiva que es propia de la situación cinematográfica y de la construcción de la ilusión de realidad en el cine, es incorporada en la reflexión de Reyes bajo el régimen de catarsis ${ }^{12}$.

Su planteo supera la posibilidad de la representación: "Cada gesto humano, cada perfil de la civilización moderna está destinado a vibrar en la pantalla: amigo míos: estamos viviendo. (Léase: estamos construyendo el cine)" (Casanova 139). Esta relación entre captación, obra y vibración está inspirada en el mismo sustrato que su llamado al museo dinámico, similar también a la movilidad de lo escultural que sostendrá en "La escultura de lo fluido", cuando piensa en la materialidad que el cine propone a los sentidos, esa "visión de estados o etapas en el flujo de lo sucesivo" (Reyes, OC VIII 388), que opondrá a la ambición de la escultura de atrapar un momento exclusivo y esencial de ese transcurrir. Con humor no exento de admiración, recordará Reyes los juguetes de barro de un pesebre en donde "los pobres indios escultores" habían representado el vapor invisible saliendo de los hocicos de los animales "escultura de una vibración térmica, escultura de un tren de ondas" (390) aquello que el cine concreta.

Esta unión entre vida y arte, afín al proyecto vanguardista, en Reyes se engarza con una aspiración romántica -las raíces goethianas que animan su mirada-, que se explicita también en su interés por los alcances de la luz, y a partir de ellos, de la ciencia y lo microscópico por la imagen cinematográfica. En Una juguetería filosófica. Cine, cronofotografía y arte digital, David Oubiña entiende la historia del cine, y de sus antepasados -el cronomatógrafo o el fusil fotográfico- bajo la dialéctica tensa entre el cientificismo y el ilusionismo, el afán científico y la construcción ficcional que intenta borrar o contener los elementos que permiten la ilusión de continuidad

12 "La "catharsis" y el cine" no es reconocido ni por Reyes no por Guzmán en los respectivos libros en que incluyen sus notas sobre cine. Sin embargo, Manuel González Casanova, y estamos de acuerdo con él, se lo atribuye a Reyes tanto por el estilo como por el abordaje. Además, en otros artículos Reyes vuelve al tema: "Aparte de que en el "cine" -simbolización luminosa del movimiento- hay siempre una especie de placer fisiológico que toca al psicólogo naturalista explicar. Aquella lejanía, aquella ritualidad que el griego buscaba para su teatro en el uso del coturno que agiganta y de la máscara que "deshumaniza", es pues, más accesible para el "cine" que para el teatro" (Casanova 156). 
y naturalidad cinematográfica. Esa primera vertiente científica encarnada por Marey "despreciaba" las posibilidades indiciales del cine, su capacidad de captación de lo real "tal como lo vemos", ya que si alguna puerta abría la nueva técnica era la de superar las limitaciones de los sentidos, la posibilidad de ver lo que de otro modo no se vería y superar así las falencias de la percepción. Desde una apreciación afín, Reyes ensalza el "cine científico":

¿A nadie se le ha ocurrido (¡Oh Fabre, gran poeta de Avignon!) montar un laboratorio especial para presentar en el cine los amores de los alacranes y de las arañas, o la perseverancia del escarabajo sagrado? Un procedimiento especial de iluminación instantánea por medio de la chispa eléctrica permite ya fotografiar la trayectoria de las balas. ¿Cuándo lo veremos en el cine? Es así como nuestros sentidos ganan capacidad sobre el caos externo, y vamos, poco a poco, penetrando en la región inhollada del ultravioleta y el ultrarrojo (Casanova 331).

La referencia a Jean Henry Fabre, poeta y entomólogo, es un acto de fe en la posibilidad de concretar una forma de conocimiento transversal ciencia-arte. El recorte que el cine opera de los cuerpos, que en la pantalla pierden su totalidad y se transforman en cabezas, ojos y dedos de tamaño gigantesco, es visto por Reyes como una capacidad expresiva -evidentemente- pero también de conocimiento:

Todo lo que pueden sugerir los técnicos de lo infinitamente pequeño y lo infinitamente grande. Pues es bien sabido que, en cuanto abandonamos nuestra escala media, habitual, comenzamos a ver milagros: productos de la multiplicación inferiores a sus factores, líneas rectas que son el camino más largo, instantes que se deshacen en ruido, pesos que se vuelven luz, etc. (Casanova 384 ).

Al referirse a una película de 1912, El féretro de cristal, Reyes concluye que por lo minucioso, esa cinta se complace en un análisis "no realista" del movimiento: "Casi puede decirse que, en estas cintas, el cine crea los moldes puros del movimiento o, por lo menos, nos enseña a percibirlos: el proceso de una mano que desarticula cuidadosamente las piezas de algún mecanismo primoroso, o que sigue con cautela, acariciándolo, el contorno de un mueble" (Casanova 141-2). En esta forma no-realista se condensan las posibilidades científicas del cine, pero también las cualidades estéticas que dan nacimiento a nuevas formas de percepción, un modelo de encuadre por el que el cine explora nuevas formas estéticas de lo visible ya no necesariamente determinadas por el paradigma pictórico clásico: "Aquellas manos, aquellos ojos que parecen suspendidos en el aire, recuerdan, en efecto, El hombre invisible" (Casanova 144) ${ }^{13}$.

13 David Oubiña relata el conflicto que genera la famosa secuencia del salto del caballo que toma Muybridge. Aquellas imágenes demostraron que, efectivamente, hay un momento en el galope del caballo en que los cuatro cascos del animal están en el aire. Pero las polémicas estallan por otros motivos: lo que resulta difícil de asimilar es esa imagen sin armonía, casi grosera, que muestra al animal en una postura muy diferente a la que le había consagrado la iconografía clásica. 
El interés por lo que no se ve, o por lo que se ve de otro modo, se desliza en Reyes hacia otro foco de atención en relación con el cine, el de la luz, que fija la materia sensible que es la película y que, tal como lo señala Loiseleux, es el elemento intrínseco a la experiencia cinematográfica, en que confluyen ciencia, técnica y arte. La luz, motivo de exploración para cineastas, artistas y pintores, en el cine pondera sus capacidades expresivas y es, en definitiva, según Loiseleux, una técnica "al servicio de la emoción". La luz es el elemento por excelencia que excita la unión de las formas del arte, de la vida y de cierta existencia del mundo y de las cosas, además del antiguo sentido que la identifica con la percepción y el pensamiento. En "Halo de ilusión microscópica" Héctor Perea comenta un artículo madrileño de Reyes, "Vermeer y la novela de Proust", donde el mexicano destaca el vínculo que unió a Vermeer con Van Leeuwenhoek, el inventor del microscopio, y los imagina juntos "contemplando las maravillas de la luz que circula por la contextura minuciosa de todas las cosas" (cit. en Perea 98). Vinculando a Vermeer con Proust, Reyes añade: "Este procedimiento de apariciones extáticas, que paulatinamente la luz analiza y descifra, hasta metamorfosear los cuerpos en almas ¿no es, con mucho, el procedimiento de Marcel Proust” (Ibíd.) ${ }^{14}$.

Cuando Reyes considera los aspectos de la luz en el cine, sus ensayos tocan una dimensión más "visionaria”, que también merece pensarse en relación con la recepción del primer cine. Hay que recordar cuán numerosos fueron los textos de carácter hipotético que proliferaron entre los trabajos críticos sobre el primer cine, considerado en un "estado" de arte y tecnología inicial, infantil, - "Nous étions du même âge mental: javais sept ans et je savis lire, il en avait douze et ne savait pas parler" (Sartre 53)- que invitaba a medirlo sobre todo por lo que sería, o lo que podría ser. Esta posibilidad y promisión es la partida de nacimiento del cine, sus alcances de arte futuro, en el caso de Reyes, animado por esta dialéctica entre lo científico y lo ficcional que trama circuitos de tensión en los desarrollos técnicos, teóricos y creativos de las exploraciones cinematográficas. La idea de un arte futuro es central para el modo en que concibe el cine, porque allí se permite un llamado ansioso sobre sus posibilidades, por una vía especulativa que en Reyes alcanza el grado de ejercicio estético e intelectual.

La especulación o proyección imaginativa es un elemento clave para entender la concepción que Reyes tiene de la literatura, que define como "verdad sospechosa". En La experiencia literaria, afirma: "Sumariamente definidas las principales actividades del espíritu, la filosofía, se ocupa del ser; la historia y la ciencia, del suceder real, perecedero en aquella, permanente en esta; la literatura, de un suceder imaginario, aunque integrado -claro es- por los elementos de la realidad, único material del que disponemos para nuestras creaciones" (14). No asombra, por eso, que este suceder imaginario que es para Reyes la literatura -en la que, recordemos, el ensayo, ese centauro de los géneros, ocupa un lugar privilegiado- encuentre un terreno particularmente

14 También Perea señala la relación arte-ciencia que se reitera en el pensamiento de Reyes cuando considera la caricatura como "un esqueleto de luz" en que el foco eléctrico queda reducido a la fibra incandescente (114). 
propicio cuando habla de cine. Las elucubraciones que Reyes propone sobre las películas son sugerencia y actividad literaria, fabuladora, intelectual, estimulada por el carácter virgen del terreno que transita. La especulación es una pieza fundante de la inteligencia de Reyes, y hay que decir que el cine, con su carácter de posibilidad, de promesa hacia el futuro, era un campo fértil para el lucimiento de esta especulación:

A propósito: ¡quién viera en el cine al hombre invisible de Wells tal como este lo concibió! Imagine el lector las escenas de robos y de combates: las plantas de los pies que se hacen ligeramente perceptibles en el polvo y en el lodo de la calle; los días de lluvia, una forma humana transparente y brillante como una fantástica pompa de jabón; el efecto de la escena en que el hombre invisible se va despojando de sus vestiduras, disfraces y vendajes para escapar a sus perseguidores; el mendigo de quien se ha apoderado, que resopla por esos caminos con un fardo a cuestas; el gato desvanecido, cuyos ojos brillan en el espacio y, en fin, la lenta reaparición del hombre invisible a medida que la muerte va endureciendo las células de su organismo (Casanova 144).

El deslizamiento hacia el lenguaje científico con que cierra el párrafo coincide con otra fabulación de Reyes, aquella en la que propone una posible película de Jekyll y Hyde, donde nuevamente desestima las posibilidades del cine para la reflexión filosófica o psicológica, descarta las elucubraciones morales o existenciales respecto de la experiencia del individuo dual y recupera, por el contrario, la afinidad del cine con el carácter científico, con la comprensión y percepción de la experiencia de la escisión del individuo que se da en la luz.

"Yo he soñado con ver este asunto reducido al cinematógrafo, pero no de una manera textual -como lo representa, y lo representa muy bien, el actor March- sino enriqueciéndolo precisamente con aquello que el cinematógrafo puede darle y la literatura sólo sugiere. He aquí lo que yo haría con el tema del hombre doble" (Reyes, OC VIII 384). Lo que sigue es un nuevo texto hipotético, una elucubración lúdica en que la separación entre los dos seres la produce una técnica en que lo visual confluye con lo eléctrico (las descargas ya clásicas del relato gótico) ${ }^{15}$ :

Sea un físico, un sabio que casi mete ya los dedos por los intersticios del éter. A través de vistosas descargas eléctricas y raros aprovechamientos de ondas que recorrerían toda la escala (radio, infrarrojo, luz, ultravioleta, röntgen, gamma, rayos cósmicos, sin olvidar las ondas acústicas y una serie de experiencias fantásticas sobre las que llamaríamos ondas del olfato y energías táctiles), acaba por operar un prodigio: acierta en retardar en medio millonésimo de segundo el índice de velocidad natural del rayo luminoso que rebota contra el espejo. Y esto basta para divorciar al objeto de su imagen (384).

15 Se trata de un extraordinario artículo de 1932, "Un drama para el cine", una contrapropuesta a la película "E hombre y el monstruo", que Rouben Mamoulian dirige en 1931, basada en la novela El extraño caso del Dr. Jekyll y Mr. Hyde de Robert Louis Stevenson y protagonizada por Fredric March. 
El divorcio del objeto con su imagen, momento de parto de Hyde en esta película hipotética, tiene aquí un doble sentido evidente. Se refiere a la trama que había concebido Stevenson, pero es también, y justamente, lo que el cine pone en funcionamiento por su carácter de duplicación de lo real. Así, en la reflexión de Reyes, la duplicación de Jekyll-Hyde se corresponde con la duplicación cinematográfica, y, en este punto Reyes insinúa una potencialidad perversa, algo que en el cine aparece como una potencialidad intrínseca: ese instante de disociación sensorial, "ondas del olfato y energías táctiles" que desencadenan la ruptura.

El tema del laboratorio debe ser recurrente y volver constantemente a lo largo de la historia [...] casos maravillosos de cambios en las dimensiones relativas; visualización -en proyección cinematográfica- de eras anteriores de la tierra, mediante la captación de un rayo de luz que regresa de su viaje en torno al universo; y todo lo que pueden sugerir los técnicos de lo infinitamente pequeño y lo infinitamente grande. Pues es bien sabido que, en cuanto abandonamos nuestra escala media, habitual, comenzamos a ver milagros: productos de la multiplicación inferiores a sus factores, líneas rectas que son el camino más largo, instantes que se deshacen en ruido, pesos que se vuelven luz, etc. (384).

El argumento sugiere la dimensión fáustica del impulso científico, los peligros de esta unión, lo que en la imaginaria película de Jekyll y Hyde, Reyes denominará "la autonomía del reflejo (que es como ir creando un universo nuevo de objetos y seres)" y que supone una doble reflexión: la de esta separación creadora entre la persona y su imagen, arte perfecto cinematográfico, pero también la pulsión fáustica que la técnica cinematográfica misma libera, y cuyo carácter la implica.

"Ya tenemos a nuestro sabio partido en dos por el tajo óptico del espejo", escribe Alfonso Reyes:

El hombre de azogue -ya liberado- sale de la luna biselada y empieza a vivir por cuenta propia. ¿Por cuenta propia? Hasta cierto punto: él repetirá por el mundo exactamente los mismos movimientos que va ejecutando su paradigma, la persona misma del sabio que le ha dado origen y viene a ser su ley trascendente: pero no podrá hacer más acciones -objetivamente hablando- que las que le dicte su figura melliza. Donde el sabio hace una caridad, el espectro hace un don funesto (386).

El final que Reyes imagina es el del agotamiento de la imagen, que es también un agotamiento del soporte:

Luchando uno contra otro, y sin poder alcanzarse nunca por el medio millonésimo de segundo que los separa y los coloca en dos universos virtuales diferentes, ambos se van debilitando, atenuando, desvaneciéndose gradualmente en el éter de que están hechos. Ya se esfuman como si mutuamente se devoraran, ya son transparentes. Ya, al fin, se reducen a una vaga ondulación, a un péndulo 
apenas sensible, a un vaivén de vaga sustancia, donde una malla vibratoria se teje y desteje de un lado para otro: tal la telaraña de reflejos que lanza un cubo de agua en el sol. Aquella rauda y leve palpitación gravita insensiblemente hacia una escritura, y traza de repente la misma fórmula algebraica que había permitido al sabio -en el primer acto- disociar los haces del espejo. En la pantalla de proyección sólo queda -rastros de ceniza- un borroso jerogliflo matemático. El sabio y su imagen desaparecieron, digeridos en un rayo de luz (387).

El esfuerzo visual que la prosa de Reyes ensaya en este imaginario desenlace -la telaraña de reflejos, la malla vibratoria, el cubo del agua al sol- bosqueja el regreso al orden, la desaparición del científico y de su imagen, el desvanecimiento de lo visual representativo en haces de luces, en vibraciones de luminiscencia, el movimiento y la imagen-emoción, tal como lo había concebido Germaine Dulac en su cinematografía total. ${ }^{16} \mathrm{Si}$ este desenlace es perturbador, se debe a que aún en su esfuerzo por reivindicar este arte, Reyes deja asomar reparos más profundos que tienen que ver con la técnica misma de lo cinematográfico, esta materia de luz que digiere sus propias producciones, de repente contrastada con la materia escrita de una fórmula que, como todo trazo escrito, tiene otra consistencia y otra perduración, o la tendría si no fuera por el soporte fílmico.

El desenlace que Alfonso Reyes imagina para Jekyll y Hyde expresa una tensión en la posibilidad cinematográfica. La misma que supone la reflexión de Reyes cuando en la época de las polémicas por el desarrollo de una cinematografía sonora, a contracorriente con el avasallador rechazo que la introducción del sonoro encontró entre los intelectuales, y en particular entre los escritores, Reyes imagina una dimensión que sobrepasa lo visual, la introducción de aquello que no se ve, es decir, una potencia más allá de lo visual: "El nuevo elemento sonoro enriquece los asuntos, no a manera de adorno (éste es el error de los directores), sino porque añade también otra ironía, otro toque estético posible; por ejemplo, la presencia de lo ausente..."(Reyes, "Nota sobre el cine". OC VIII 380).

Su reflexión sobre el cine no fue unívoca, significaba avanzar por un terreno desafiante, un espacio utópico por excelencia que deja ver el intrincado cruce que en Reyes se da entre la reflexión intelectual, la especulación y la pulsión imaginativa. Los riesgos de este tránsito, los detecta muy bien, por ejemplo, cuando discute la validez científica de los trabajos de Goethe, en particular sobre el carácter de la luz. Entonces, con cierta astucia, Reyes modifica el eje de discusión. Admite que en el período de especialización de la época del alemán ya era difícil para un no especialista lanzarse a terrenos que se hacían cada vez más delimitados y concretos: si debe considerar al Goethe científico no es por la certitud de su pensamiento sino porque aquellas ideas

16 “...cine entendido como arte del movimiento y de los ritmos visuales de la vida y de la imaginación" (98). 
"constituyen elementos esenciales en la concepción del universo a que llegó Goethe. Solo en tal concepto nos importan". (Reyes, OC XXVI 62). En otra parte, con un dejo nostálgico, se referirá al "espectáculo de la integridad goethiana" (Reyes, OC XXVI 425) como una época definitivamente acabada, imposible de transitar para un pensador contemporáneo, viendo en Goethe un último intento de hacerlo, y también los albores de un fracaso. En el caso de Reyes, el cine le propone este terreno de integridad y cruces, que también es el de su propia prosa, en la que bajo las formas de la especulación y de lo futuro indaga una realización de lo artístico, la reconciliación con el carácter empírico y científico de la experiencia, la obra del porvenir. La otra cara del cine, la de la industria y la de la cultura de masas, Reyes no la ignora, pero su mundo de intereses, de conocimiento y de valores traza allí un límite autoimpuesto que lo empuja a la reflexión sobre las posibilidades más vanguardistas del medio (con la excepción del momento en que vincula cine y narración épica, una afirmación rotunda pero cuyos alcances, en definitiva, renuncia a discutir). Cabe como coda que algunos desarrollos contemporáneos de la forma cinematográfica -los trabajos de videastas recientes que se niegan a los efectos cinéticos como modo de representación transparente y se apropian de mecanismos de corte y fragmentación, y el giro hacia el documental- también confirman los tanteos primigenios de Reyes.

\section{Referencias}

Banda, Daniel y Moure, José. Le cinéma: naissance d’un art. Premiers écrits (1895-1920) . Paris: Flammarion, 2008. Medio impreso.

Baudelaire, Charles. Curiosités esthétiques et autres écrits sur l'art. Paris: Herman, 1968. Medio impreso.

Benjamin, Walter. "La obra de arte en la época de la reproductibilidad técnica". Benjamin, Walter. Conceptos de filosofía de la historia. Trad. H. A. Murena y D. J. Vogelmann. Buenos Aires: Caronte, 2007. Medio impreso.

Bongers, Wolfgang, María José Torrealba y Ximena Vergara. Archivos y letrados. Escritos sobre cine en Chile: 1908-1940. Santiago: Cuarto propio, 2011. Medio impreso.

Borge, Jason. Avances de Hollywood: crítica cinematográfica en Latinoamérica 19151945. Rosario: Beatriz Viterbo, 2005. Medio impreso.

Canudo, Ricciotto. "Manifiesto de las siete artes". Textos y Manifiestos del cine. Joaquim Romaguera i Ramió y Homero Alsina Thevenet (Eds.). Madrid: Cátedra, 2010. Medio impreso.

de los Reyes García-Rojas, Aurelio. "Alfonso Reyes, censor de película”. Alfonso Reyes y los territorios del arte. Raquel Tibol, Minerva Margarita Villarrreal, Adolfo Castañón, Manuel González Casanova (Eds.). México: Museo Nacional de Arte-México, 2009. Medio impreso. 
Duffey, Patrick. «Un dinamismo abrasador: La velocidad del cine mudo en la literatura iberoamericana de los años veinte y treinta.» Revista Iberoamericana Vol LXVIII, 199 (Abril- Junio 2002): 417-440. Medio impreso.

Dulac, Germaine. «Las estéticas. Las trabas. La cinegrafía integral.» Textos y manifiestos del cine. Joaquim Romaguera i Ramió y Homero Alsina Thevenet (Eds). Madrid: Cátedra, 2010. Medio impreso.

Goic, Cedomil. «Alfonso Reyes o el deslinde literario.» Anales de la Universidad de Chile 117 (1960): 71-77. Medio impreso.

Gonzalez Casanova, Manuel. El cine que vio Fósforo. Alfonso Reyes y Martín Luis Guzmán. México: Fondo de Cultura Económica, 2003. Medio impreso.

González Casanova, Manuel. Por la pantalla. Génesis de la crítica cinematográfica en México 1917-1919. México: Dirección General de actividades cinematográficas. UNAM, 2000. Medio impreso.

Loiseleux, Jacques. La luz en el cine. Cómo se ilumina con palabras. Cómo se escribe con la luz. Madrid: Paidós, 2005. Medio impreso.

Martínez, José Luis. Guía para la navegación de Alfonso Reyes. México: UNAM, Cátedras, 1992. Medio impreso.

Oubiña, David. Una juguetería filosófica. Cine, cronofotografía y arte digital. Buenos Aires: Manantial, 2009. Medio impreso.

Perea, Héctor. Ojos de Reyes. México: Textos de Difusión Cultural UNAM, 2009. Medio impreso.

Reyes, Alfonso. La experiencia literaria. México: Fondo de Cultura Económica, 1989. Medio impreso.

---. Obras Completas Vol VIII. México: Fondo de Cultura Económica, 1996. Medio impreso.

---. Obras completas Vol. IX. México: Fondo de Cultura Económica, 1996. Medio impreso.

---. Obras Completas Vol. XX. México: Fondo de Cultura Económica, 1979. Medio impreso.

---. Obras completas Vol. XXVI. México: Fondo de Cultura Económica, 1993. Medio impreso.

Reyes, Alfonso y Federico Luis Marín Guzman y de Onis. "Frente a la pantalla”. Cuadernos de cine 6. México: UNAM, 1963. Medio impreso.

Romaguera i Ramió, Joaquim y Homero Alsina Thevenet. Textos y manifiesto del cine. Estética. Escuelas. Movimientos. Disciplinas. Innovaciones. Madrid: Cátedra, 2010. Medio impreso.

Sadoul, Georges. Historia del cine mundial. México: Siglo XXI, 2010. Medio impreso. Sánchez Prado, Ignacio. «El giro (post)humanista. A manera de Introducción.» Revista de Crítica Literaria Latinoamericana 68 (2008): 7-18. Medio impreso. 
Sartre, Jean Paul. Jérôme Prieur. Le spectateur nocturne. Les écrivains au cinéma. Paris: Editions de l'Etoile. Cahiers du cinéma, 1993. 52-54. Le spectateur nocturne. Les écrivains au cinéma

Xavier, Ismael. El discurso cinematográfico. La opacidad y la transparencia. Buenos Aires: Manantial, 2008. Medio impreso.

Recibido: 19 enero 2014

Aceptado: 09 junio 2014 